\title{
A Laboratory Study on the Geotechnical Characteristics of Sand- Bentonite Mixtures and the Role of Particle Size of Sand
}

\author{
V. Srikanth ${ }^{1} \cdot$ A. K. Mishra ${ }^{1}$
}

Received: 22 September 2015/Accepted: 28 December 2015/Published online: 19 January 2016

(C) Springer International Publishing Switzerland 2016

\begin{abstract}
Mixtures of sand and bentonite are generally used as a liner material at the waste disposal site. Sand is added to bentonite to achieve a higher compaction density and lower desiccation shrinkage. A review of the literature showed that most of the past research works has focused to study the influence of bentonite on the various geotechnical properties of sand-bentonite mixtures. Although sand occupies a larger proportion in a sand-bentonite mixture, the effect of proportion of sand and its particle size on the characteristics of the sand-bentonite mixture is still unclear as very little information is available. This study is an attempt to understand the effect of the particles size of the sand on the behaviour of various sand-bentonite mixtures mixed in different proportions. Various mixtures of fine sand-bentonite and medium sand (MS)-bentonite were prepared by varying the sand content from 50 to $90 \%$ by dry weight of the mix. Mixtures were tested for Atterberg limits, compaction characteristics, swelling and hydraulic behaviour. Results indicated that variation in liquid limit is not linear even though the clay content in the mixes varied linearly; mixtures with fine sand (FS) displayed relatively higher liquid limits compared to MS counterparts. FS mixtures exhibit relatively high optimum moisture content and low maximum dry density. Consolidation test indicated that irrespective of the sand particle size, mixes with bentonite content $<20 \%$ showed a general lack of appreciable swelling. This implied that bentonite content available was not sufficient for filling the voids created by sand skeleton. For
\end{abstract}

\footnotetext{
A. K. Mishra

anilmishra@iitg.ernet.in

V. Srikanth

v.srikanth@iitg.ac.in

1 Indian Institute of Technology, Guwahati 781039, India
}

the same bentonite content, mixtures with FS displayed relatively higher swelling pressure and lower hydraulic conductivity. For a given void ratio, FS mixtures exhibited lowest hydraulic conductivity for all bentonite contents.

Keywords Sand-bentonite mixture · Atterberg limits . Swelling pressure $\cdot$ Swelling potential hydraulic conductivity

\section{Introduction}

Compacted soil-bentonite mixtures have been used as a liner material at the waste disposal site and as a buffer material at the nuclear waste repository. Clay liner, which is an integral part of a landfill, acts as a barrier between the leachates and the ground water to prevents the ground water from being contaminated due to migration of the leachate. Similarly, the buffer material protects the canister, which is used to store the nuclear waste material, from being coming in contact with water and getting corroded. Therefore, achieving a low hydraulic conductivity [1] is considered the key objective amongst other important parameters like desiccation susceptibility [2], compressibility, thermal conductivity [1], longevity [1], shear strength, resistance to chemical attack [3] etc. while selecting materials for the use as a liner and buffer application [4].

Due to its high swelling, lower hydraulic conductivity and contaminant adsorption capacity, bentonite forms an integral part of a liner and buffer material. However, high compressibility, high desiccation shrinkage, low shear strength and low compaction density [5] are reasons of concern. Generally, a locally available soil, such as sand, is mixed with bentonite to improve its certain engineering characteristics like maximum dry density, shrinkage [5], 
shear strength, and thermal conductivity [6]. When bentonite is added to sand, due to its very small particle size, it occupies the pore space present between the individual sand grains. Once the bentonite comes in contact with water, it starts to swell and fill these void spaces resulting in a decrease in the hydraulic conductivity of the mixture [1, 7].

Various researchers have suggested of adding different proportions of sand to bentonite to achieve the required specification for the liner and buffer applications. From their studies Mollins [8] found that the addition $5 \%$ of bentonite to sand can achieve the hydraulic conductivity criteria of $10^{-9} \mathrm{~m} / \mathrm{s}$ required for a liner material for the use at a landfill disposal site [4, 9]. Cowland and Leung [10] had suggested of adding a high quality bentonite in the range of 5-7 \% to a completely weather granite to achieve the desired design hydraulic conductivity value for liner material. Similarly, Hoeks et al. [11] had suggested of adding 5-15\%, whereas, Gueddouda et al. [12] suggested of adding $12 \%$ bentonite to local soils to achieve the design hydraulic conductivity value for a landfill liner.

A review of literature on the behaviour of sand-bentonite mixtures indicated that sand, which has been used as a filler material, has only been considered for its volumetric stability in the mixture and no importance has been given to assess its effect due to variation in its particle size distribution on the behaviour of sand-bentonite mixture. Most of the previous researchers have focused only to study the impact of bentonite proportions and quality on the behaviour of sand-bentonite mixture.

Few studies have been carried out in the past to investigate the effect of the particle size on the behaviour of sand-bentonite mixture. To understand the effect of mixing silt and sand sized materials with bentonite on liquid limit, Sivapullaiah and Sridharan [13] conducted a series of tests by adding bentonite to silt and sand in various proportions and concluded that at same bentonite content mixtures with fine sand (FS) exhibits higher liquid limit in comparison to the mixtures with coarse sand. Though shrinkage limit is influenced by the type of clay minerals and amount of clay present, Sridharan and Prakash [14] concluded that shrinkage of clay-sand mixture is not a plasticity characteristic as it was thought before; instead, it is a function of relative particle size distribution.

Jong et al. [15] used clay-spherical glass beads mixture to study the influence of particle size and concentration of glass beads on the shrinkage characteristics of clay and observed that at low clay content the glass beads were in contact with each other and the clay particles oriented parallel around the glass beads. Due to this arrangement a higher porosity and consequently a higher shrinkage limit was observed by the mixtures.

Clay clods are formed at lower water content due to flocculation nature of clay particles $[16,17]$ and influences significantly on the hydraulic conductivity [17, 18]. To study the clod size on hydraulic conductivity, Benson and Daniel [18] used different clod sizes (4.8-19 mm) and observed a six fold decrease in the hydraulic conductivity value for the smallest clod size and concluded that the hydraulic conductivity of a compacted soil also a function of clay clod size. Dixon et al. [10] observed that with the increase in the sand content in the bentonite the maximum dry density increases, whereas, the optimum moisture content and volumetric shrinkage due to drying decreases. Gueddouda et al. [12] observed that with increase in the sand content in a sand-bentonite mixture the friction angle, hydraulic conductivity increases and swelling potential decreases. Using mixtures of bentonite and locally available Mikawa silicate with bentonite content varying from 5 to $50 \%$, Komine [7] reported that that hydraulic conductivity decreases as the bentonite content increases in the mixture and the decrease in the hydraulic conductivity was particularly notable for bentonite contents in the range of 5-20\%. However, a further increase in the bentonite content in the mixture did not decrease the hydraulic conductivity appreciably indicating most of the void spaces formed by the non-swelling particles gradually filled up by the swollen bentonite up to a bentonite content of $20 \%$ and as almost no voids left for the swollen bentonite to fill, a marginal decrease in the hydraulic conductivity occurred due to further addition of bentonite. Sridharan et al. [19] and Sivapullaiah et al. [20] attempted to explain the influence of the grain size of non-swelling soil on the swelling behaviour of soil-bentonite mixtures and observed a rise in hydraulic conductivity value with increase in coarse fraction in the mixture.

A review of the past studies clearly suggests that the sand content has a definite controlling behaviour on the various engineering properties of sand-bentonite mixtures; where, the behaviour depends on how effectively the bentonite fills the void space formed between the sand particles. Since the void space between the sand particles depends on the particle size of sand, which may vary from sand to sand depending upon its gradation, it is quite essential to study the effect of sand particle size on the behaviour of sand-bentonite mixture. Hence, the main objective of this study was to investigate the effect of proportion of sand of different sizes on the behaviour of sand-bentonite mixtures.

\section{Materials and Methods}

To investigate the effect of sand content of a particular size on the behaviour of sand-bentonite mixture, a locally available sand was used for this study. Further, to investigate the influence of the bentonite quality on sand- 
bentonite mixture, two bentonites of different mineralogical composition and swelling properties were selected for the study and procured from Rajasthan state of India. These bentonites are named as Bentonite-1 (or B1) and Bentonite2 (or B2) in the further discussion for brevity. Bentonite-1 (B1) was a moderately swelling bentonite, whereas, Bentonite-2 (B2) was a higher swelling bentonite. After a thorough wash with de-ionized (DI) water, sand was sieved following the guidelines provided in ASTM D 422-63 [21] by using a sieve shaker and then separated into two groups, i.e. FS (i.e. $0.075-0.425 \mathrm{~mm}$ ) and medium sand (MS) (i.e. $0.425-2 \mathrm{~mm}$ ).

Liquid limit test was performed on bentonites using Casagrande's liquid limit test apparatus in accordance with ASTM D 4318 [22]. Both wet sieve analysis and hydrometer analysis were performed in order to determine the particle size distribution of bentonites. Standard proctor test was conducted as per ASTM D 698 [23] to obtain optimum moisture content (OMC) and maximum dry density (MDD) of bentonites. Various properties of bentonite used in the study are presented in the Table 1.

Fine and MS were added to both of the bentonites separately in a proportion of 50-90 \% by dry weight and were

Table 1 Characteristics of bentonites used in the study

\begin{tabular}{lcc}
\hline Properties $(\%)$ & Bentonite-1 & Bentonite-2 \\
\hline Clay & 52.2 & 68.0 \\
Silt & 43.4 & 28.3 \\
Sand & 4.4 & 3.7 \\
Liquid limit & 346.1 & 609.2 \\
Plastic limit & 33.0 & 41.5 \\
Shrinkage limit & 23.0 & 10.4 \\
\hline
\end{tabular}

tested for Atterberg limits, compaction characteristics, and one dimensional consolidation characteristics. Liquid limit of the mixtures was determined by cone penetration method as suggested by Sivapullaiah and Sridharan [13]. Compaction characteristics of sand-bentonite mixtures were determined by standard protector compaction method as per ASTM D 698 [23] and tabulated in Table 2.

Consolidation test was carried out in a standard consolidometer according to ASTM D 2435 [24] to assess the hydraulic conductivity and compressibility behaviour. Mollins et al. [8] indicated that due to swelling nature of bentonite the consolidation testing data is more suitable than other methods for hydraulic conductivity determination of the sand-bentonite mixtures with bentonite content $>5 \%$. To bring out the significance of the water content on the behaviour of mixtures, each mixed were compacted at $5 \%$ dry of OMC, OMC and $5 \%$ wet of OMC.

Each sample was packed in an airtight polythene bag and left for a period of $24 \mathrm{~h}$ in a desiccator for moisture equilibrium. Samples of $60 \mathrm{~mm}$ diameter and $15 \mathrm{~mm}$ thickness were made by statically compacting the moisture equilibrated soil to its corresponding MDD. An allowance of $5 \mathrm{~mm}$ was given between the top of soil specimen and consolidation ring to accommodate the swelling upon water intake [25]. The entire assembly was placed in the consolidation cell and positioned in the loading frame with a seating pressure of $4.9 \mathrm{kPa}$, distilled water was added at top cap and allowed to swell until the swelling was completed and corresponding vertical swelling with time was measured. Then samples were consolidated by increasing the pressure gradually by an increment ratio of 1 (i.e. increased by $4.9,9.8,19.6 \mathrm{kPa}$ at each step) to a maximum pressure of $784.5 \mathrm{kPa}$. For each pressure increment the change in the thickness of soil sample was measured from the dial gauge
Table 2 Atterberg limits for sand-bentonite mixtures

\begin{tabular}{|c|c|c|c|c|c|c|c|c|}
\hline \multirow[t]{2}{*}{ Sand-bentonite proportions } & \multicolumn{4}{|c|}{ Bentonite-1 (B1) } & \multicolumn{4}{|c|}{ Bentonite-2 (B2) } \\
\hline & LL & PL & PI & SL & LL & PL & PI & SL \\
\hline \multicolumn{9}{|l|}{ Medium sand (MS) } \\
\hline $50: 50$ & 69 & 25 & 44 & 24 & 145 & 18 & 127 & 25 \\
\hline $60: 40$ & 55 & 21 & 34 & 29 & 125 & 17 & 108 & 30 \\
\hline $70: 30$ & 50 & 19 & 30 & 31 & 97 & 20 & 77 & 37 \\
\hline $80: 20$ & 33 & 17 & 17 & 28 & 74 & 19 & 55 & 38 \\
\hline $90: 10$ & 32 & NP & NP & 30 & 47 & NP & NP & 34 \\
\hline \multicolumn{9}{|l|}{ Fine sand (MS) } \\
\hline $50: 50$ & 80 & 19 & 60 & 22 & 171 & 22 & 149 & 23 \\
\hline $60: 40$ & 61 & 17 & 44 & 29 & 139 & 24 & 115 & 32 \\
\hline $70: 30$ & 48 & 19 & 29 & 33 & 102 & 25 & 77 & 37 \\
\hline $80: 20$ & 42 & 18 & 24 & 37 & 74 & 33 & 41 & 40 \\
\hline $90: 10$ & 33 & NP & $\mathrm{NP}$ & 35 & 48 & 33 & 15 & 40 \\
\hline
\end{tabular}

$L L$ liquid limit (\%), $P L$ plastic limit (\%), PI plasticity index, $S L$ shrinkage limit (\%) 
readings. The change in the void ratio corresponding to the increase in the overburden pressure was calculated as,

$\Delta e=\Delta \mathrm{H}\left(1+e_{0}\right) / \mathrm{H}$

where, $\Delta \mathrm{H}$ is the change in the thickness of sample due to increase in pressure; $\mathrm{H}$ is the initial thickness of the sample and $e_{0}$ is the initial void ratio.

The coefficient of volume change was calculated as,

$m_{\mathrm{v}}=-\frac{\Delta \sigma}{\Delta e} \times\left(1+e_{0}\right)$

where, $\Delta \sigma$ is the change in pressure and $\Delta e$ is the change in void ratio.

Coefficient of consolidation $\left(c_{\mathrm{v}}\right)$ was determined by Taylor's square root of time fitting method given.

$c_{\mathrm{v}}=\frac{D^{2} T_{\mathrm{v}}}{t_{90}}$

where, $t_{90}$ is the time for $90 \%$ degree of consolidation.

The hydraulic conductivity at each pressure increment, $k$, was calculated using the coefficient of consolidation $c_{\mathrm{v}}$, coefficient of volume change, $m_{v}$ and unit weight of water, $\gamma_{\mathrm{w}}$, as

$k=m_{\mathrm{v}} c_{\mathrm{v}} \gamma_{\mathrm{w}}$

\section{Results and Discussion}

\section{Atterberg Limits}

The plasticity characteristic of sand-bentonite mixture depends upon the clay content and the type of clay mineral present in the bentonite [13]. The data in Table 2 shows that the liquid limit of the mixtures varied non-linearly even though the variation in clay content was linear. For the same proportion of sand-bentonite mixture, bentonite with FS exhibited a higher liquid limit value in comparison to the bentonite with MS. However, the difference in the liquid limit value gets reduced with the increase in the sand content in the mixture. The data in Table 2 indicates that for the mixtures with a sand content of $70 \%$ and higher, the sand, irrespective of its particle size, strongly influences and dictates the shearing resistance of the sand-bentonite mixture. Similarly, the data also showed that the liquid limit of mixture significantly depends on the size of sand particles. Data in Table 2 also shows that the shrinkage limit of the mixture increased with an increase in the sand content in the mixture. Similar observation was also observed by Jong and Warkentin [15]. Since at the shrinkage limit the capillary water present in the pore space starts to evaporate [14], for a given sand-bentonite mixture, FS-bentonite mixtures displayed a higher shrinkage limit indicating the effect of large number of tiny voids and the difficulty involved in removing water from such tiny voids in comparison to a few large voids formed because of the relatively lager sand particles in MSbentonite mixtures. The data also showed that the relative difference in shrinkage limits between FS and MS mixtures of same proportion increased with the increase in the sand content and was more prominent for a sand content of $70 \%$ and higher. The data for the shrinkage limit also indicated that bentonites with FS were relatively less susceptible to volume changes with a change in water content in comparison to the bentonite with MS of same proportion. Atterberg limits for mixtures with sand content of $70 \%$ and beyond indicates a stark shift in the behaviour i.e. being influenced by clay content to those being sand dependent.

\section{Compaction Characteristics}

The data from the compaction test in Table 3 shows that for the same proportion, the FS-bentonite and MS-bentonite mixture exhibited different OMC and MDD value indicating a possible influence of sand particle size on the compaction characteristics of the mixtures. Mixtures with MS resulted in relatively a higher MDD and lower OMC values for both the bentonites which can be attributed to the effective filling of the bentonite particle in the void spaces formed between the sand particles. Data in Table 3 shows that the mixtures with $80 \%$ sand content exhibited the highest density among all mixtures. Once the void spaces formed between the individual sand particles get completely filled by the bentonite, with a further addition the bentonite occupies the space outside the void space and decreases the density after imbibing water.

Table 3 Compaction characteristics of various sand-bentonite mixtures

\begin{tabular}{|c|c|c|c|c|}
\hline \multirow{2}{*}{$\begin{array}{l}\text { Sand- } \\
\text { bentonite } \\
\text { proportions }\end{array}$} & \multicolumn{2}{|c|}{ Bentonite-1 (B1) } & \multicolumn{2}{|c|}{ Bentonite-2 (B2) } \\
\hline & $\begin{array}{l}\text { OMC } \\
(\%)\end{array}$ & $\begin{array}{l}\text { MDD } \\
\left(\mathrm{kg} / \mathrm{m}^{3}\right)\end{array}$ & $\begin{array}{l}\text { OMC } \\
(\%)\end{array}$ & $\begin{array}{l}\mathrm{MDD} \\
\left(\mathrm{kg} / \mathrm{m}^{3}\right)\end{array}$ \\
\hline \multicolumn{5}{|c|}{ Medium sand } \\
\hline $50: 50$ & 22.5 & 1565 & 12.9 & 1598 \\
\hline $60: 40$ & 19.0 & 1628 & 11.6 & 1624 \\
\hline $70: 30$ & 16.0 & 1662 & 17.5 & 1657 \\
\hline $80: 20$ & 15.0 & 1710 & 18.5 & 1651 \\
\hline $90: 10$ & 18.5 & 1670 & 17.9 & 1611 \\
\hline \multicolumn{5}{|l|}{ Fine sand } \\
\hline $50: 50$ & 22.5 & 1585 & 20.9 & 1555 \\
\hline $60: 40$ & 20.5 & 1595 & 20.2 & 1582 \\
\hline $70: 30$ & 18.0 & 1655 & 18.8 & 1607 \\
\hline $80: 20$ & 18.4 & 1701 & 20.5 & 1612 \\
\hline $90: 10$ & 17.2 & 1641 & 22.4 & 1579 \\
\hline
\end{tabular}




\section{Swelling Potential and Swelling Pressure}

When compacted sand-bentonite mixture is allowed to hydrate, water gets absorbed by the montmorillonite into the interlayers of montmorillonite resulting in an increase in the volume. The extent of volume change is strongly dependent on the bentonite content of the mixture, initial mixing water content and initial dry density. Elsbury et al. [26] suspected that particle size distribution of the mixture might have an influence on the swelling and hydraulic characteristics of the mixture. Swelling pressure and swelling potential exhibited by various sand-bentonite mixtures are presented in Tables 4, 5, 6 and 7. From the data in the tables the swelling pressure and swelling potential can be seen to be decreasing with increasing sand content irrespective

Table 4 Swelling Pressure results of sand-Bentonite-1 mixtures

\begin{tabular}{|c|c|c|c|}
\hline \multirow{2}{*}{$\begin{array}{l}\text { Sand-bentonite } \\
\text { proportions }\end{array}$} & \multicolumn{3}{|c|}{ Swelling pressure $(\mathrm{kPa})$} \\
\hline & MDD-OMC & $\begin{array}{l}\text { MDD-5 \% } \\
\text { dry of OMC }\end{array}$ & $\begin{array}{l}\text { MDD-5\% } \\
\text { wet of OMC }\end{array}$ \\
\hline \multicolumn{4}{|c|}{ Medium sand (MS) } \\
\hline $50: 50$ & 56.0 & 106.1 & 88.7 \\
\hline $60: 40$ & 31.8 & 106.9 & 45.5 \\
\hline $70: 30$ & 33.2 & 96.2 & 25.4 \\
\hline $80: 20$ & 15.2 & 17.6 & 11.8 \\
\hline $90: 10$ & 1.1 & 1.5 & 0.9 \\
\hline \multicolumn{4}{|l|}{ Fine sand (FS) } \\
\hline $50: 50$ & 246.9 & 282.6 & 217.5 \\
\hline $60: 40$ & 230.5 & 272.8 & 215.2 \\
\hline $70: 30$ & 81.3 & 140.5 & 59.6 \\
\hline $80: 20$ & 16.1 & 18.2 & 12.1 \\
\hline $90: 10$ & 1.3 & 1.8 & 1.1 \\
\hline
\end{tabular}

Table 5 Swelling pressure results of sand-Bentonite-2 mixtures

\begin{tabular}{lccc}
\hline $\begin{array}{l}\text { Sand-bentonite } \\
\text { proportions }\end{array}$ & \multicolumn{3}{l}{ Swelling pressure $(\mathrm{kPa})$} \\
\cline { 2 - 4 } & MDD-OMC & $\begin{array}{l}\text { MDD-5 } \% \\
\text { dry of OMC }\end{array}$ & $\begin{array}{c}\text { MDD-5 } \% \\
\text { wet of OMC }\end{array}$ \\
\hline $\begin{array}{l}\text { Medium sand (MS) } \\
\text { 50:50 }\end{array}$ & 340.5 & 388.4 & 335.3 \\
60:40 & 300.1 & 219.1 & 242.2 \\
70:30 & 134.4 & 215.8 & 50.4 \\
80:20 & 23.5 & 79.7 & 21.2 \\
$90: 10$ & 10.2 & 0 & 0 \\
Fine sand (FS) & & & \\
$50: 50$ & 372.2 & 431.7 & 343.3 \\
60:40 & 344.4 & 258.9 & 332.3 \\
$70: 30$ & 79.5 & 101.0 & 71.5 \\
$80: 20$ & 52.6 & 94.7 & 21.6 \\
$90: 10$ & 7.8 & 10.1 & 5.0 \\
\hline
\end{tabular}

of initial compaction condition. The data shows that, for any given mix proportion, the samples compacted on the dry side of OMC exhibited a higher swelling potential followed by those compacted at OMC. A comparison between the mixtures with FS and MS showed that sand with FS exhibited relatively higher swelling pressure and swelling potential for any given mix proportion. Irrespective of the particle size of sand, mixtures with bentonite content $<20 \%$ showed a general lack of appreciable swelling. Mixture with high bentonite contents (i.e. 50 and $40 \%$ ) exhibited very high values of swelling pressures and swelling potential. For the same bentonite content mixtures with FS displayed relatively higher swelling pressure and swelling potential compared to mixture with MS. For all mix proportions mixtures with Bentonite-2, being a higher swelling bentonite,

Table 6 Swelling Potential results of sand-Bentonite-1 mixtures

\begin{tabular}{llll}
\hline $\begin{array}{l}\text { Sand-bentonite } \\
\text { proportions }\end{array}$ & \multicolumn{2}{l}{ Swelling potential $(\%)$} \\
\cline { 2 - 4 } & MDD-OMC & $\begin{array}{l}\text { MDD-5 } \% \\
\text { dry of OMC }\end{array}$ & $\begin{array}{l}\text { MDD-5 \% } \\
\text { wet of OMC }\end{array}$ \\
\hline Medium sand (MS) & & \\
50:50 & 1.9 & 3.8 & 2.9 \\
$60: 40$ & 1.4 & 6.2 & 1.2 \\
$70: 30$ & 1.0 & 2.8 & 0.2 \\
$80: 20$ & 0.3 & 0.5 & 0.1 \\
$90: 10$ & 0.1 & 0.1 & 0.1 \\
Fine sand (FS) & & & \\
$50: 50$ & 9.6 & 11.8 & 15.8 \\
$60: 40$ & 9.0 & 15.7 & 4.3 \\
$70: 30$ & 3.5 & 3.0 & 2.1 \\
$80: 20$ & 0.3 & 0.6 & 0.1 \\
$90: 10$ & 0.1 & 0.1 & 0.1 \\
\hline
\end{tabular}

Table 7 Swelling Potential results of sand-Bentonite-2 mixtures

\begin{tabular}{lccl}
\hline $\begin{array}{l}\text { Sand-bentonite } \\
\text { proportions }\end{array}$ & \multicolumn{3}{l}{ Swelling potential $(\%)$} \\
\cline { 2 - 4 } & MDD-OMC & $\begin{array}{l}\text { MDD-5 } \% \\
\text { dry of OMC }\end{array}$ & $\begin{array}{l}\text { MDD-5 \% } \\
\text { wet of OMC }\end{array}$ \\
\hline Medium sand (MS) & & \\
50:50 & 18.7 & 35.0 & 17.0 \\
$60: 40$ & 16.2 & 8.0 & 7.8 \\
$70: 30$ & 4.6 & 18.5 & 1.6 \\
$80: 20$ & 1.0 & 6.3 & 0 \\
$90: 10$ & 0 & 0 & 0 \\
Fine sand (FS) & & & \\
$50: 50$ & 18.4 & 24.1 & 10.2 \\
$60: 40$ & 13.3 & 11.5 & 22.7 \\
$70: 30$ & 2.0 & 5.2 & 4.1 \\
$80: 20$ & 1.4 & 7.4 & 1.1 \\
$90: 10$ & 0.2 & 0.2 & 0.2 \\
\hline
\end{tabular}


resulted in higher swelling potential and swelling pressure compared to Bentonite-1. A comparison between the mixtures shows that, for the same proportion of sand-bentonite, bentonite with FS content exhibited a higher value of swelling potential and swelling pressure in comparison to bentonite with MS. Bentonite effectively fills the smaller void spaces present between the individual FS particles in comparison to relatively larger void spaces between the MS particles. Once the void spaces between FS particles are filled the bentonite, with a further increase in the volume of the bentonite it will start to push the sand particles resulting in a higher value of swelling potential and swelling pressure. Similarly, data also shows that mixtures with Bentonite-2, which has a higher swelling capacity, exhibited a higher swelling potential and swelling pressure values in comparison to mixtures with Bentonite- 1 further indicating the dependence of the swelling potential and swelling pressure on the filling up the pore spaces between the sand particles.

\section{Hydraulic Conductivity}

The influences of bentonite content and initial compaction condition on hydraulic conductivity of different sandbentonite mixtures are presented in the Figs. 1, 2, 3, 4, 5 and 6. Hydraulic conductivity of a compacted soil layer is
Fig. 1 Void ratio-hydraulic conductivity plot for sand-B1 mixtures compacted at MDD

Fig. 2 Void ratio-hydraulic conductivity plot for sand-B1 mixtures compacted at $5 \%$ wet of optimum
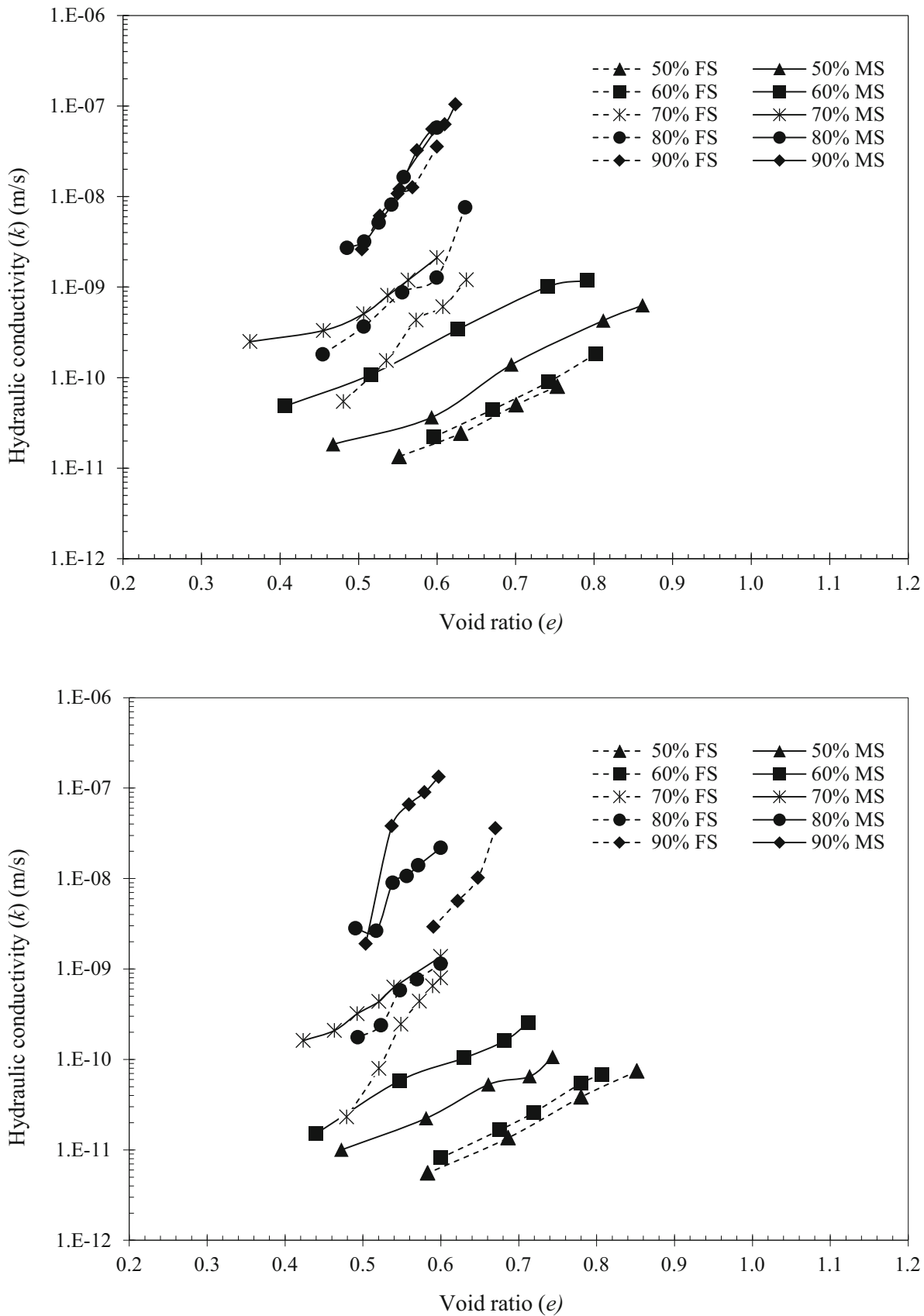
Fig. 3 Void ratio-hydraulic conductivity for sand-B1 mixtures compacted at $5 \%$ dry of optimum

Fig. 4 Void ratio-hydraulic conductivity plot for sand-B2 mixtures compacted at MDD
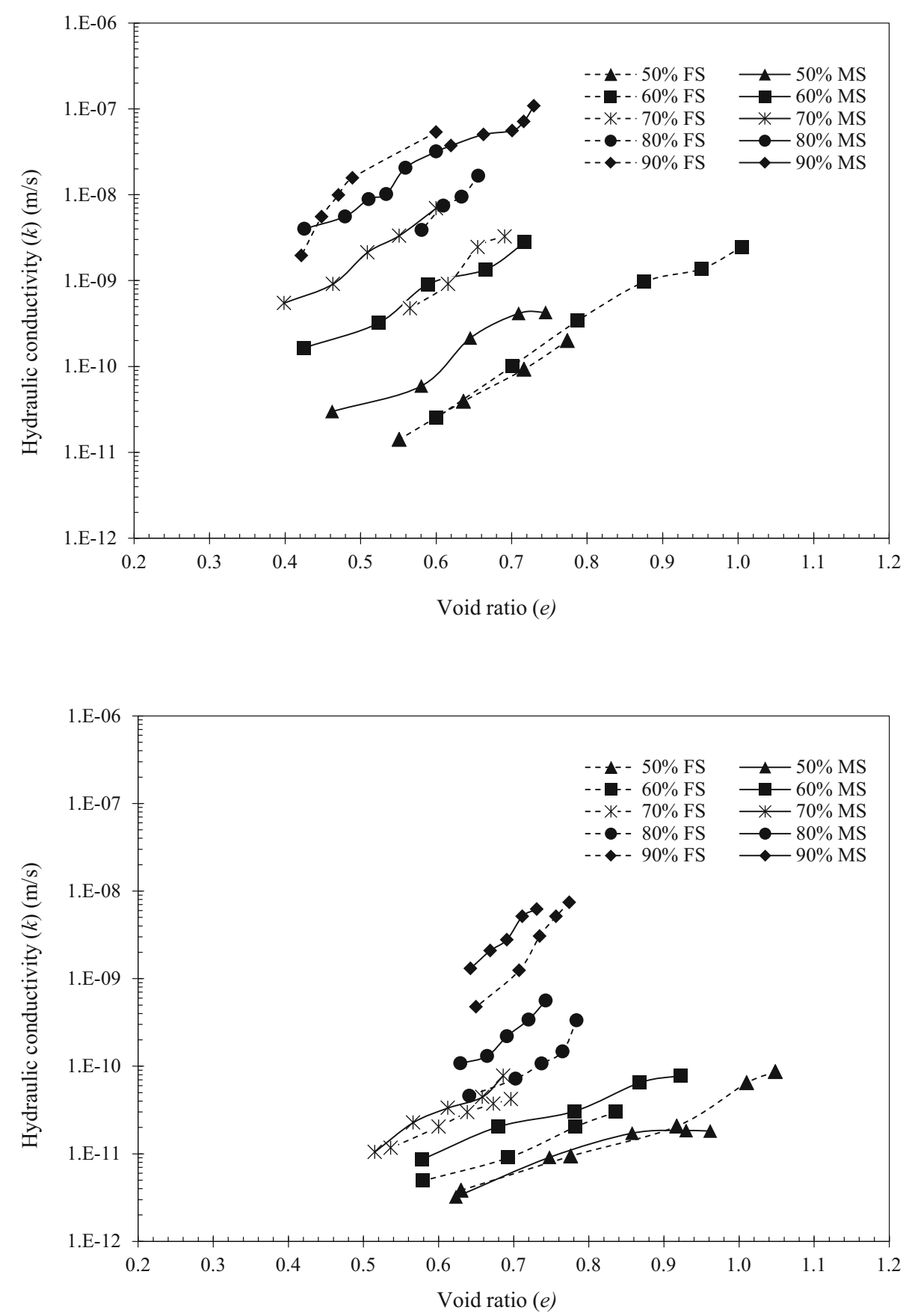

defined and dominated by the network of interconnected voids introduced because of mixing water content, compaction techniques, workmanship etc. [27]. Bentonite occupies the voids created by sand matrix in a compacted sand-bentonite mixture and when the bentonite gets hydrated fully, it swells and tries to fill the voids thereby effectively reducing the hydraulic conductivity of the compacted mixture. Lambe [28] observed that arrangement of soil particles or fabric plays a dominant role in hydraulic conductivity of compacted soils.
Result for all the mixtures show that irrespective of the initial compaction condition, mixtures with higher bentonite content possessed a lower value of the hydraulic conductivity. For any given mix proportion, FS-bentonite mixtures exhibited lower hydraulic conductivity in comparison to MS-bentonite mixtures. Samples compacted at $5 \%$ wet of OMC displayed lowest hydraulic conductivity while those compacted at $5 \%$ dry of OMC displayed highest conductivity and samples compacted at OMC remained intermittent, Benson and Daniel [18] attributed 
Fig. 5 Void ratio-hydraulic conductivity plot for sand-B2 mixtures compacted at $5 \%$ wet of optimum

Fig. 6 Void ratio-hydraulic conductivity for sand-B2 mixtures compacted at $5 \%$ dry of optimum
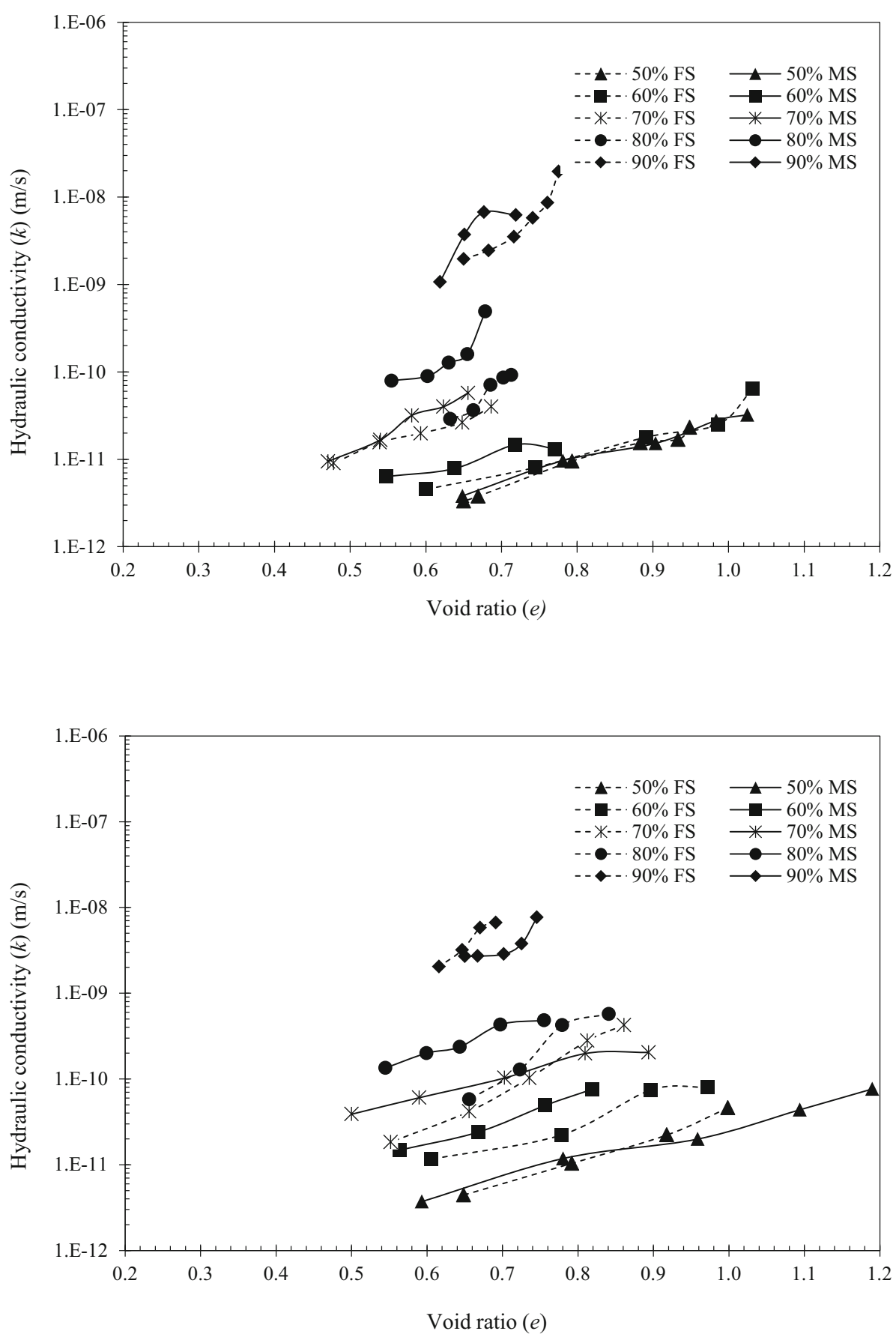

this phenomenon to the formation of soil clods at low moulding water content and their gradual breakdown with increasing water content resulting in a lower hydraulic conductivity.

Figure 7 and 8 shows the effect of sand proportion and particle size on the hydraulic conductivity of sand-bentonite mixture at a particular void ratio. Figure 7 compares the hydraulic conductivity value of different sandBentonite-1 mixtures, mixed in various proportions at a void ratio of 0.6. Similarly, Fig. 8 compares the hydraulic conductivity value of different sand-Bentonite- 2 mixtures, mixed in various proportions at a void ratio of 0.65 . The plots show that irrespective of type of bentonite present in the mixture, for the same proportion of sand, mixture with MS exhibited a higher value of hydraulic conductivity in comparison to mixture with FS. This can be attributed to the inability of bentonite to fill the large pores formed in the MS particles resulting in a higher value of hydraulic 
Fig. 7 Void ratio-hydraulic conductivity for sand-B1 mixtures at a void ratio of 0.60

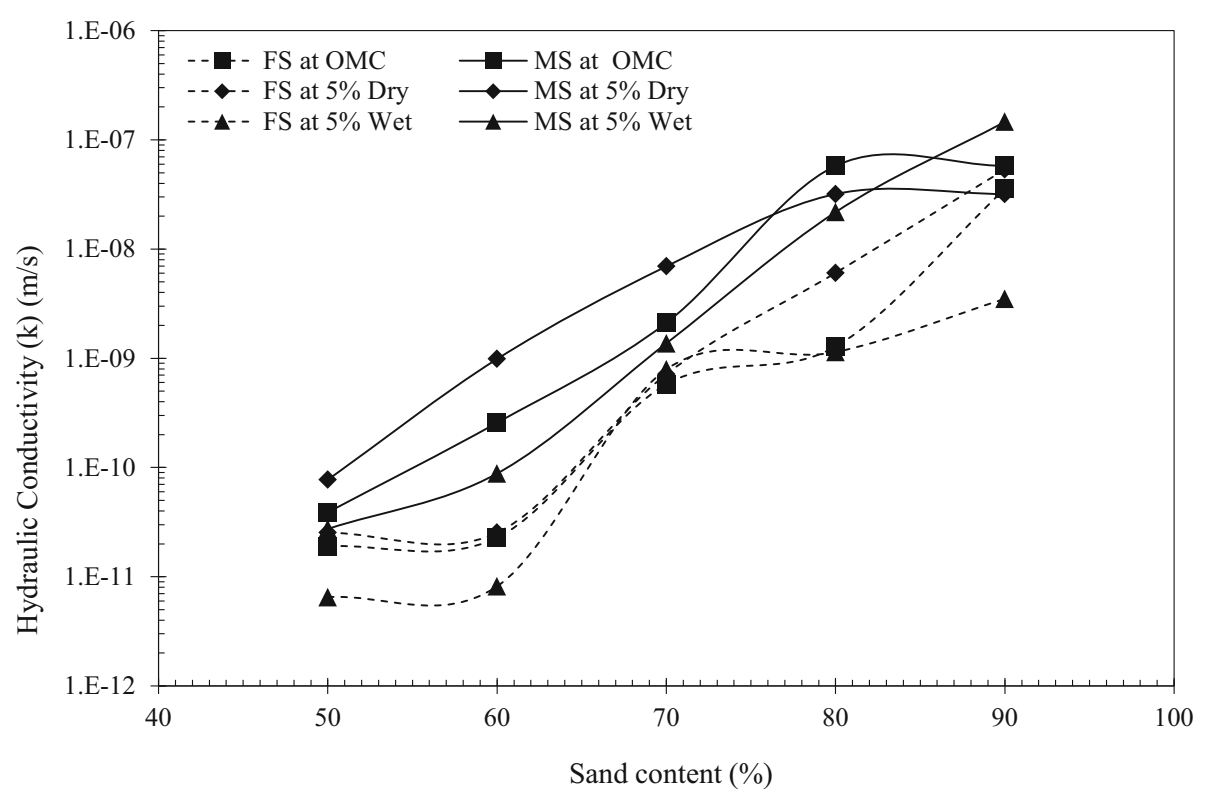

Fig. 8 Void ratio-hydraulic conductivity for sand-B2 mixtures at a void ratio of 0.65

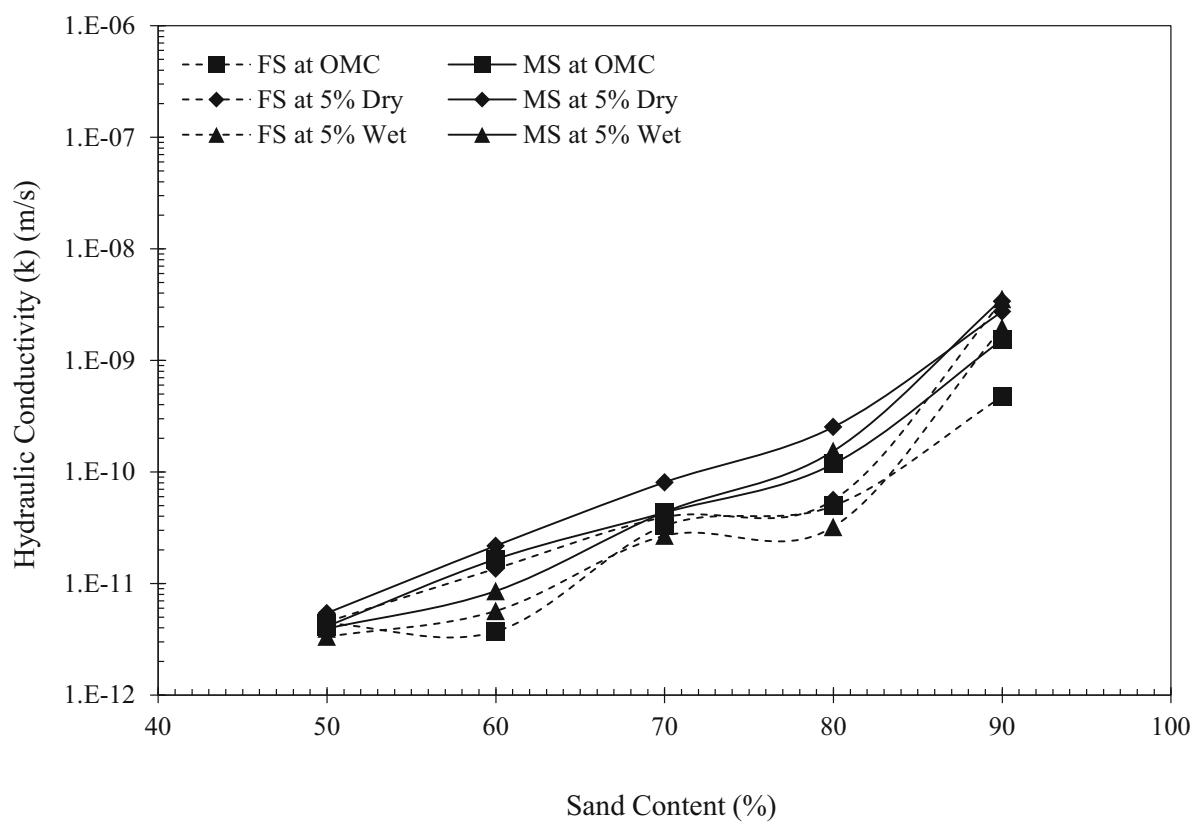

conductivity. The plots in Figs. 7 and 8 also show that the difference in the hydraulic conductivity between the mixtures of $50 \% \mathrm{FS}+50 \% \mathrm{~B} 1$ and $60 \% \mathrm{FS}+40 \% \mathrm{~B} 1$ was very less indicating $40 \%$ of Bentonite- 1 is well enough to fill the void space present between the FS completely. The plot in Fig. 8 shows that for any given proportion of the mix, the difference in the hydraulic conductivity between the mixtures of FS and MS with Bentonite-2 was marginal indicating the effectiveness of Bentonite-2 to fill the pore space owing to its higher swelling capacity.

\section{Conclusions}

The following conclusions were drawn from the work presented above;

1. For any given proportion of sand-bentonite mixtures, FS mixes were observed to be more plastic and high swelling than MS mixes

2. Shrinkage limit was observed to be increasing with sand content, which again is relatively higher in case of FS-Bentonite mixtures 
3. Bentonite with MS exhibited higher MDD as compared to mixture of bentonite with FS of similar proportion

4. Swelling characteristics obtained from the tests showed that bentonite content $<20 \%$ was insufficient in filling the void spaces created by sand matrix

5. For a given bentonite content, bentonite with FS exhibited relatively a lower hydraulic conductivity value possibly due to the effective filling of voids created by sand matrix

6. Hydraulic conductivity of sand-bentonite mixtures are very much dependent upon particle size of sand among other things like bentonite content, mixing water content, compaction energy used and quality of bentonite used etc.

\section{References}

1. Komine H, Ogata N (1999) A trial design of buffer materials from the viewpoint of self-sealing, In: Proceedings of radioactive waste management and environmental remediation, ASME

2. Kleppe JH, Olson RE (1985) Desiccation cracking of soil barriers hydraulic barriers in soil and rock. Hydraul Barriers Soil Rock ASTM STP 874:263-275

3. Madsen FT, Mitchell JK (1988) Chemical effects on clay fabric and hydraulic conductivity. Landfill 20:201-251

4. Daniel DE, Benson CH (1990) Water content-density criteria for compacted soil liners. J Geotech Eng 116(12):1811-1830

5. Dixon DA, Gray MN, Thomas AW (1985) A study of the compaction properties of potential clay-sand buffer mixtures for use in nuclear fuel waste disposal. Eng Geol 21(3-4):247-255

6. Graham J, Saadat F, Gray MN, Dixon DA, Zhang QY (1989) Strength and volume change behaviour of a sand-bentonite mixture. Can Geotech J 26(2):292-305

7. Komine H (2004) Simplified evaluation on hydraulic conductivities of sand-bentonite mixture backfill. Appl Clay Sci 26(1-4):13-19

8. Mollins LH (1996) Predicting the properties of bentonite-sand mixtures. Clay Miner 31(2):243-252

9. United States Environmental Protection Agency (USEPA) (1988) Design, construction and evaluation on of clay liners for waste management facilities. Technical Resource Document, Hazardous Waste engineering Research Laboratory, Office of Research and Development, U. S. Environmental Protection Agency, Cincinnati, EPA/530-SW- 86-007F, NTIS PB 86-184496

10. Cowland JW, Leung BN (1991) A field trial of a bentonite landfill liner. Waste Manag Res 9(1):277-291

11. Hoeks J, Glas H, Hofkamp J, Ryhiner AH (1987) Bentonite liners for isolation of waste disposal sites. Waste Manag Res 5(1):93-105

12. Gueddouda MK, Lamara M, Aboubaker N, Taibi S (2008) Hydraulic conductivity and shear strength of dune sand-bentonite mixtures. Electron J Geotech Eng 13:1-15

13. Sivapullaiah PV, Sridharan A (1985) Liquid limit of soil mixtures. Geotech Test J 8(3):111-116

14. Sridharan A, Prakash K (2000) Shrinkage limit of soil mixtures. Geotech Test J 23(1):3-8

15. Jong ED, Warkentin BP (1965) Shrinkage of soil samples with varying clay concentration. Can Geotech J 2(1):16-22

16. Olsen HW (1962) Hydraulic flow through saturated clays. Clays Clay Miner 9:131-161

17. Daniel DE (1984) Predicting hydraulic conductivity of clay liners. J Geotech Eng 110(2):285-300

18. Benson CH, Daniel DE (1990) Influence of clods on the hydraulic conductivity of compacted clay. J Geotech Eng 116(8):1231-1248

19. Sridharan A, Rao A, Sivapullaiah PV (1986) Swelling pressure of clays. Geotech Test J 9(1):24-33

20. Sivapullaiah PV, Sridharan A, Stalin VK (2000) Hydraulic conductivity of bentonite-sand mixtures. Can Geotech J 37(2):406-413

21. ASTM D 422-63 (2007) Standard test method for particle-size analysis of soils, American Society for Testing and Materials (ASTM), Philadelphia

22. ASTM D 4318 (2000). Standard test methods for Liquid Limit, Plastic Limit, and Plasticity Index of Soils, American Society for Testing and Materials (ASTM), Philadelphia

23. ASTM D 698 (2012). Standard test methods for laboratory compaction characteristics of soil using standard effort, American Society for Testing and Materials (ASTM), Philadelphia

24. ASTM D 2435 (1996.) standard test method for one-dimensional consolidation properties of soils. American Society for Testing and Materials (ASTM), Philadelphia

25. Sun D, Cui H, Sun W (2009) Swelling of compacted sand-bentonite mixtures. Appl Clay Sci 43(3-4):485-492

26. Elsbury BR, Daniel DE, Sraders GA, Anderson DC (1990) Lessons learned from compacted clay liner. J Geotech Eng 116(11):1641-1660

27. Benson CH, Hardianto FS, Moran ES (1994) Representative specimen size for hydraulic conductivity assessment of compacted soil liners. ASTM STP 1142:3-29

28. Lambe TW (1954) The permeability of compacted fine-grained soils. Special Tech Publ 163:55-67 